\section{BMJ Open Respiratory Research}

\title{
Ambient air pollution and risk of respiratory infection among adults: evidence from the multiethnic study of atherosclerosis (MESA)
}

\author{
Kipruto Kirwa, ${ }^{1}$ Carly M Eckert, ${ }^{1}$ Sverre Vedal, ${ }^{1}$ Anjum Hajat, ${ }^{2}$ Joel D Kaufman ${ }^{3}$
}

To cite: Kirwa K, Eckert CM, Vedal S, et al. Ambient air pollution and risk of respiratory infection among adults: evidence from the multiethnic study of atherosclerosis (MESA). BMJ Open Resp Res 2021;8:e000866. doi:10.1136/ bmjresp-2020-000866

- Additional material is published online only. To view, please visit the journal online (http://dx.doi.org/10. 1136/bmjresp-2020-000866)

Received 20 December 2020 Revised 1 February 2021 Accepted 5 February 2021
Check for updates

(c) Author(s) (or their employer(s)) 2021. Re-use permitted under CC BY-NC. No commercial re-use. See rights and permissions. Published by BMJ.

${ }^{1}$ Department of Environmental and Occupational Health Sciences, University of Washington School of Public Health, Seattle, Washington, USA

${ }^{2}$ Department of Epidemiology, University of Washington School of Public Health, Seattle, Washington, USA ${ }^{3}$ Departments of Environmental and Occupational Health Sciences, Medicine, and Epidemiology, University of Washington, Seattle, Washington, USA

Correspondence to Kipruto Kirwa; kirwa@uw.edu

\section{ABSTRACT}

Background Air pollution may affect the risk of respiratory infection, though research has focused on uncommon infections or infections in children. Whether ambient air pollutants increase the risk of common acute respiratory infections among adults is uncertain, yet this may help understand whether pollutants influence spread of pandemic respiratory infections like COVID-19. Objective To estimate the association between ambient air pollutant exposures and respiratory infections in adults. Methods During five study examinations over 12 years, 6536 participants in the multiethnic study of atherosclerosis (MESA) reported upper respiratory tract infections, bronchitis, pneumonia or febrile illness in the preceding 2 weeks. Using a validated spatiotemporal model, we estimated residential concentrations of ambient $\mathrm{PM}_{2.5}, \mathrm{NO}_{\mathrm{x}}$ and $\mathrm{NO}_{2}$ for the 2-6 weeks (short-term) and year (long-term) prior to each examination.

Results In this population aged 44-84 years at baseline, $10 \%-32 \%$ of participants reported a recent respiratory infection, depending on month of examination and study region. $\mathrm{PM}_{2.5}, \mathrm{NO}_{\mathrm{x}}$ and $\mathrm{NO}_{2}$ concentrations over the prior 2-6 weeks were associated with increased reporting of recent respiratory infection, with risk ratios $(95 \% \mathrm{Cls})$ of 1.04 (1.00 to 1.09), 1.15 (1.10 to 1.20) and 1.21 (1.10 to 1.33 ), respectively, per increase from 25 th to 75 th percentile in residential pollutant concentration. Conclusion Higher short-term exposure to $\mathrm{PM}_{2.5}$ and traffic-related pollutants are associated with increased risk of symptomatic acute respiratory infections among adults. These findings may provide an insight into the epidemiology of COVID-19.

\section{INTRODUCTION}

Exposure to ambient air pollutants is a wellestablished risk factor for several adverse respiratory outcomes. ${ }^{1-3}$ Long-term exposure to particulate and gaseous pollutants has been associated with negative impacts on pulmonary function in adults and children, ${ }^{4} 5$ increased risk of asthma development, ${ }^{6}$ increased severity of chronic obstructive pulmonary disease (COPD) symptoms, ${ }^{7}$ faster progression of emphysema ${ }^{8}$ and incidence of malignant neoplasms of the lung. ${ }^{9}$

\section{Key messages}

Is exposure to ambient air pollutants associated with respiratory infection in adults?

- An increase in residential concentration of $\mathrm{PM}_{2.5}, \mathrm{NO}$ and $\mathrm{NO}_{2}$ from the 25th to the 75th percentile in the previous $2-6$ weeks period was associated with $4 \%$, $15 \%$ and $21 \%$ higher risk of reporting a respiratory infection.

- These findings indicate that fine particulate and traffic-related air pollutants may increase the risk of respiratory infection among adults.

Short-term exposure is associated with worsening of pulmonary function in adults, ${ }^{10} 11$ aggravation of asthma and bronchitis in adults and children ${ }^{12} 13$ and increased incidence, hospitalisation and mortality due to respiratory tract infections. ${ }^{14-17}$

Short and long-term exposure to air pollutants may impair host immune defenses, resulting in increased susceptibility to respiratory infections. ${ }^{1819}$ Most prior research on air pollutants and respiratory infections has focused on impacts among children ${ }^{20} 21$ or individuals with cystic fibrosis. ${ }^{22-24}$ However, the link between pollutant exposure and acute respiratory infections among adults has received comparatively less attention, even as mortality rates due to lower respiratory infections (LRI) among children under 5 years have declined globally without corresponding improvements in the adult population. ${ }^{25}$

Acute respiratory infections among adults are common and represent a major source of disease burden. ${ }^{26}$ The number of LRI-linked deaths among people above 70 years old rose from nearly 750000 to 1.1 million annually between 2000 and $2016 .^{25}$ Acute respiratory infections account for approximately 5 million emergency department visits in the USA yearly, and for the largest share $(41 \%)$ of antibiotics prescribed in the adult outpatient 
setting. ${ }^{2728}$ Among individuals older than 5 years in 2016, there were approximately 11.6 million LRI episodes in the USA, and about 61 million hospitalisations globally. ${ }^{25}$ The ongoing COVID-19 pandemic and ageing global population highlight the urgent need to better understand modifiable risk factors of respiratory infections in the adult population.
While current estimates attribute the majority of the excess burden of disease from ambient air pollutants to cardiovascular causes, a potentially large and poorly estimated fraction of that burden is due to respiratory illnesses. ${ }^{1}$ The relative paucity of evidence on the association between air pollution and respiratory infections has recently been noted. ${ }^{29}$ We examined the association

Table 1 Baseline characteristics of study participants in the multiethnic study of atherosclerosis (MESA), by report of recent respiratory infection in the first five study examinations ${ }^{\star}$

\begin{tabular}{|c|c|c|c|}
\hline Characteristic & $\begin{array}{l}\text { All participants, } \\
\mathrm{n}=6536(100.0 \%)\end{array}$ & $\begin{array}{l}\text { Participants who reported } \\
\text { an infection at any } \\
\text { examination, } \\
\mathrm{n}=3167(48.5 \%)\end{array}$ & $\begin{array}{l}\text { Participants who reported } \\
\text { no infection at all } \\
\text { examinations, } \\
\mathrm{n}=3369(51.5 \%)\end{array}$ \\
\hline Age (years), mean (SD) & $62.0(10.2)$ & $61.2(10.1)$ & $62.8(10.3)$ \\
\hline \multicolumn{4}{|l|}{ Race } \\
\hline White & $2516(38.5)$ & $1157(36.5)$ & $1359(40.3)$ \\
\hline Chinese-American & $787(12.0)$ & $332(10.5)$ & $455(13.5)$ \\
\hline African-American & $1786(27.3)$ & $898(28.4)$ & $888(26.4)$ \\
\hline Hispanic & $1447(22.1)$ & $780(24.6)$ & $667(19.8)$ \\
\hline \multicolumn{4}{|l|}{ Sex } \\
\hline Female & $3445(52.7)$ & $1765(55.7)$ & $1680(49.9)$ \\
\hline Male & $3091(47.3)$ & $1402(44.3)$ & $1689(50.1)$ \\
\hline \multicolumn{4}{|l|}{ Education level } \\
\hline Less than high school & $1169(17.9)$ & $585(18.5)$ & $584(17.3)$ \\
\hline High school & $1187(18.2)$ & $570(18.0)$ & $617(18.3)$ \\
\hline Some college or technical certificate & $1858(28.4)$ & $905(28.6)$ & $953(28.3)$ \\
\hline College or graduate degree & $2322(35.5)$ & $1107(35.0)$ & $1215(36.1)$ \\
\hline Married/living with a partner & $3947(60.4)$ & $1850(58.4)$ & $2097(62.2)$ \\
\hline Body mass index, mean (SD) & $28.3(5.5)$ & $28.7(5.6)$ & $28.0(5.3)$ \\
\hline Ever smoked & 3485 (53.3) & $1697(53.6)$ & $1788(53.1)$ \\
\hline Current smoker & $741(11.4)$ & $414(13.1)$ & $327(9.8)$ \\
\hline Employed & $2838(43.4)$ & $1429(45.1)$ & $1409(41.8)$ \\
\hline \multicolumn{4}{|l|}{ Annual family income } \\
\hline$<\$ 20000$ & $1597(24.6)$ & $789(25.1)$ & $808(24.2)$ \\
\hline$\$ 20000-\$ 39999$ & $1756(27.1)$ & $880(28.0)$ & $876(26.2)$ \\
\hline$\$ 40000-\$ 74999$ & $1653(25.5)$ & $816(26.0)$ & $837(25.1)$ \\
\hline$\geq \$ 75000$ & $1474(22.7)$ & $654(20.8)$ & $820(24.5)$ \\
\hline Own home or pay mortgage & $4413(67.7)$ & $2045(64.8)$ & $2368(70.5)$ \\
\hline Excellent self-reported general health status & $1465(46.9)$ & $639(44.1)$ & $826(49.3)$ \\
\hline No health insurance & $464(7.2)$ & $233(7.4)$ & $231(6.9)$ \\
\hline On medicaid & $616(9.5)$ & $304(9.7)$ & $312(9.3)$ \\
\hline Diabetic per ADA 2003 criteria & $1052(16.1)$ & $537(17.0)$ & $515(15.3)$ \\
\hline Has metabolic syndrome & $2485(38.0)$ & $1235(39.0)$ & $1250(37.1)$ \\
\hline $\begin{array}{l}\text { Moderate and vigorous physical activity, met } \\
\text { minutes/week, median (IQR) }\end{array}$ & 3870 (1950-7080) & 4065 (2018-7328) & 3765 (1905-6840) \\
\hline $\begin{array}{l}\text { Intentional physical activity, met minutes/week, } \\
\text { median (IQR) }\end{array}$ & $810(105-1950)$ & $788(88-1875)$ & $840(158-2085)$ \\
\hline Self-reported emphysema & $73(1.1)$ & $42(1.3)$ & $31(0.9)$ \\
\hline Self-reported asthma & $253(3.9)$ & $142(4.5)$ & $111(3.3)$ \\
\hline
\end{tabular}

*Units are $n(\%)$ unless otherwise specified.

ADA, American Diabetic Association. 
between long- and short-term exposure to particulate matter less than 2.5 microns in diameter $\left(\mathrm{PM}_{25}\right)$ and oxides of nitrogen $\left(\mathrm{NO}_{\mathrm{x}}\right.$ and $\left.\mathrm{NO}_{2}\right)$ and recent occurrence of upper respiratory tract infections (URTI), bronchitis, pneumonia and febrile illness in a diverse, well-characterised cohort of adults undergoing follow-up in the multiethnic study of atherosclerosis (MESA).

\section{METHODS}

MESA is a prospective cohort study of 6814 white, African American, Hispanic and Chinese American individuals recruited from six regions in the USA (Baltimore, MD; New York City, NY; Los Angeles County, CA; Chicago, IL; Winston-Salem, NC and St. Paul, MN) primarily to investigate the progression of subclinical and clinical cardiovascular disease.$^{30}$ MESA air is an ancillary study to examine the role of air pollutants in these outcomes. ${ }^{31}$ Recruitment and baseline clinical examinations occurred between July 2000 and August 2002. By January 2012, four additional study examinations had been completed. At the first MESA examination in 2000-2002, participants were 44-84 years old and did not have clinical cardiovascular disease. We used data from the first five MESA examinations to quantify the association between longterm and short-term exposure to ambient $\mathrm{PM}_{2.5}, \mathrm{NO}_{\mathrm{x}}$ and $\mathrm{NO}_{2}$ and the occurrence of respiratory infections in the 2 weeks prior to each study examination. We excluded any observations from study visits at which a participant was taking oral steroids.

\section{Patient and public involvement}

The study design, analysis, interpretation of results and writing or editing of this research paper were made without patient involvement.

\section{Exposure estimation}

The approach to air pollutant exposure estimation in MESA has been described in detail. ${ }^{31-33}$ A hierarchical high-resolution spatiotemporal model is used to predict outdoor concentrations at each participant's residence for each 2 weeks period from January 1999 through the end of participant follow-up. Participants provided residential address information for the entire study duration. The model integrates data from US Environmental Protection Agency Air Quality System regulatory monitors, three types of MESA air-specific monitoring campaigns conducted in the study communities and at homes of study participants and hundreds of geocovariates in a universal kriging and spatial smoothing framework. $^{33-35}$ The median (range) cross-validated $R^{2}$ values of the prediction models across study regions were 0.79 (0.54-0.85) for $\mathrm{PM}_{2.5}, 0.72(0.50-0.92)$ for $\mathrm{NO}_{\mathrm{x}}$, and 0.78 $(0.45-0.90)$ for $\mathrm{NO}_{2}$. For primary analyses, timescales for assessing associations were selected a priori as the average exposure 1 year before an MESA examination (long-term exposure) and the 4 weeks starting from 14 days before an examination date (short-term exposure). We also conducted sensitivity analyses using average exposures in the 2-weeks period covering 14-28 days prior to an examination.

\section{Outcome assessment}

At each of five study examinations, participants were asked whether they had experienced or been diagnosed with a cold or influenza, febrile illness, sinus infection, bronchitis or pneumonia in the preceding 2 weeks. We constructed a composite binary variable indicating the occurrence of any of the symptoms or diagnoses.

\section{Covariate data}

Detailed demographic, anthropometric, lifestyle and medical history data were collected at each MESA clinical examination using self-administered and technicianadministered standardised questionnaires. ${ }^{30}$ We used data on age (continuous), study region, educational attainment (up to high school or more than high school), sex (male or female), race/ethnicity (white, African American, Hispanic or Chinese American), body mass index in $\mathrm{kg} / \mathrm{m}^{2}(<25,25-30$ or $\geq 30)$, current smoking status (yes or no), marital status (married or not married), annual family income in US dollars $(<20000$; 20000-39 999; 40000-74 999; $\geq 75000)$, number of people living in the household, number of children in the household, employment status (employed, retired or unemployed/homemaker), home ownership (outright owner, paying a mortgage and renting or other arrangement), having health insurance (yes or no), diagnosis of diabetes mellitus (based on the 2003 American Diabetic Association fasting criteria algorithm) ${ }^{36}$ having metabolic syndrome based on National Cholesterol Education Program guidelines ${ }^{37}$ and self-reported doctor-diagnosed asthma or emphysema. Potential confounding by neighbourhood socioeconomic status (NSES) was addressed using an NSES index derived from variables abstracted from the 2000 US Census. As earlier described, this index was obtained by summing $z$-scores calculated for six NSES variables (median value of owner-occupied housing units, proportion of residents with at least a high school diploma, percentage with at least a bachelor's degree, median household income, percentage with household income $<50000$ dollars and percent with professional/ managerial occupations). ${ }^{38}$

\section{Statistical analysis}

We applied modified Poisson regression with a sandwich linearised estimator of variance to estimate the association between occurrence of respiratory infections in the 2 weeks preceding each of five MESA clinical examinations and average long-term and short-term residential concentrations of ambient $\mathrm{PM}_{2.5}, \mathrm{NO}_{\mathrm{x}}$ and $\mathrm{NO}_{2}$, adjusting for potential confounders. In contrast to logistic regression, this method for longitudinal binary outcomes ${ }^{39}$ 


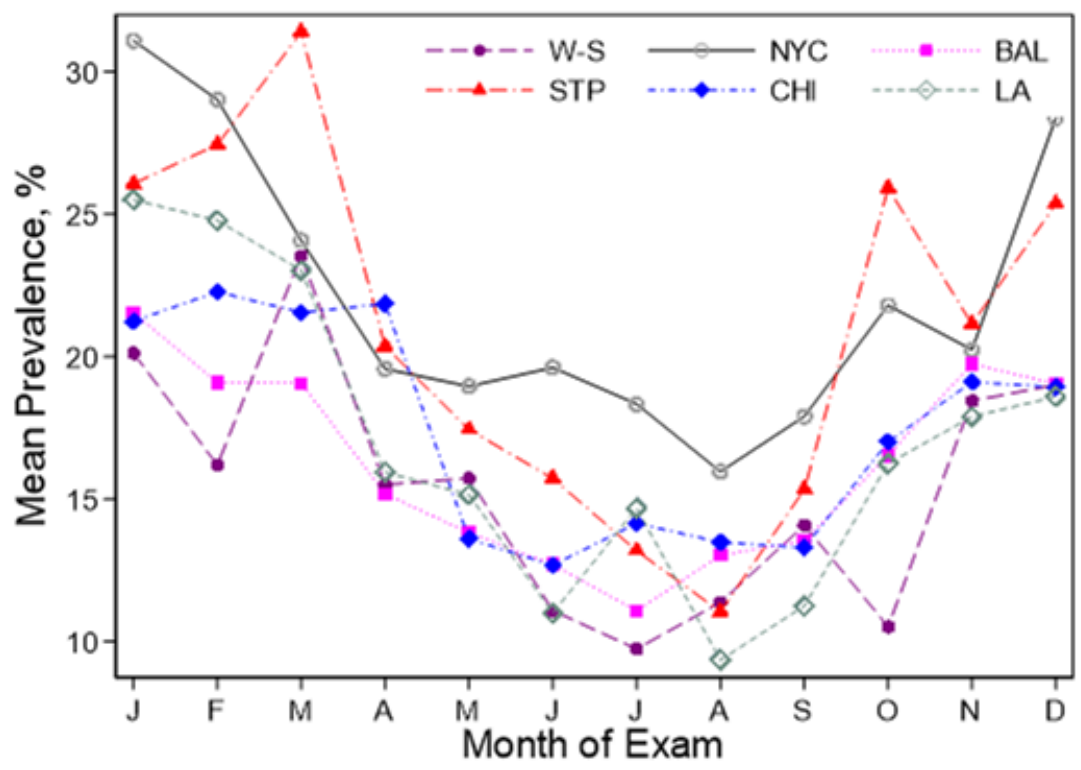

Figure 1 Prevalence of respiratory infection by region and month of examination, across five study examinations. BAL, Baltimore, MD; CHI, Chicago, IL; LA, Los Angeles, CA; NYC, New York City, NY; STP, St Paul, MN; W-S, Winston Salem, NC.

provides a direct measure of the risk ratio and is appropriate when outcomes are common.

We modelled long-term and short-term associations independently, accounting for weather, seasonality and long-term trends. In long-term models, we included smooth functions of calendar time (natural cubic splines with two degrees of freedom per year (df/year)) to account for secular temporal trends. In short-term models, we also used smooth functions of time (splines with six df/year) to account for seasonal and other timevarying influences on infection rates, and additionally included smooth functions of temperature and humidity (four $\mathrm{df}$ splines) to deal with potential confounding by weather.

We assessed whether the association between pollutant exposure and recent respiratory infection varied by strata defined by sex, race, current smoking status, age at baseline, diabetes, education level and NSES. Because modification of effects across regions by NSES has been observed in prior MESA studies, ${ }^{38}$ we examined models with study region-NSES interactions. Since occurrence of a respiratory infection may be influenced by community-wide levels of infection, we did a secondary analysis to examine if the association between reported infection and ambient pollutant concentration varied by whether the week of the study examination was classified by the Centers for Disease Control (CDC) as meeting the state-level threshold for influenza activity, defined as region-specific periods of two or more consecutive weeks in which each week accounted for more than $2 \%$ of the season's total number of specimens that tested positive for influenza in public health laboratories. ${ }^{40} \mathrm{We}$ also conducted a posthoc assessment of whether level of pollutant exposure modified the risk of infection during high vs low influenza activity periods.

Sensitivity analyses included estimation of associations separately for each of the five study examinations, and restriction to participants who were present at all examinations. Because febrile symptoms may reflect both respiratory and non-respiratory illness, we conducted an analysis excluding that symptom subcategory. We also evaluated extended models containing self-reported general health status and levels of moderate and vigorous physical activity (metabolic equivalents of minutes/week) for the baseline visit because these covariates were not available at all visits.

\section{RESULTS}

After excluding 278 participants who were missing one or more covariates at all MESA examinations, our analytical data set contained 6536 participants at baseline (table 1). We excluded 347 observations from 79 participants, on study visits at which a participant was taking oral steroids. The mean (SD) age at baseline was 62.0 (10.2) years. At baseline, $3445(52.7 \%)$ participants were female, 2516 $(38.5 \%)$ were white, $741(11.4 \%)$ were current smokers and $2322(35.5 \%)$ had at least a college education. Among Hispanic and African American participants, females and current smokers, a higher fraction reported an infection on at least one study examination than those reporting no infection at all visits (table 1).

By the fifth examination, 4547 participants who met inclusion criteria were still undergoing follow-up, of whom 4197 contributed to the analysis at all five examinations. Baseline characteristics of participants included in the analysis at all visits compared with the 2339 not 

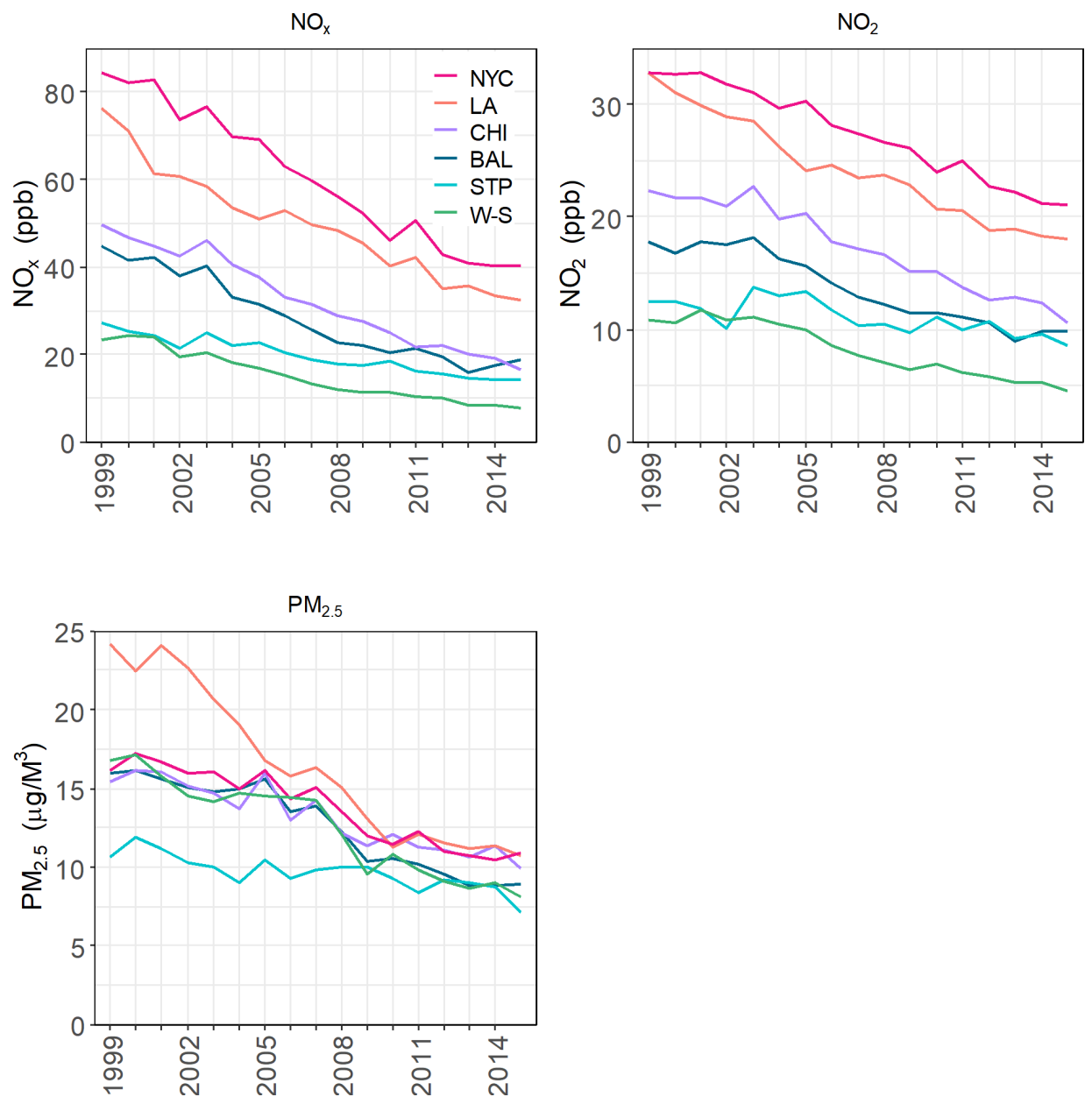

Figure 2 Yearly mean concentrations of $\mathrm{PM}_{2.5}, \mathrm{No}_{\mathrm{x}}$ and $\mathrm{NO}_{2}$ at MESA study participant locations. BAL, Baltimore, MD; CHI, Chicago, IL; LA, Los Angeles, CA; NYC, New York City, NY; STP, St Paul, MN; W-S, Winston Salem, NC. MESA, multiethnic study of atherosclerosis.

included in at least one examination are shown in online supplemental table 1. Generally, participants contributing to the analysis at all examinations were younger and reported relatively higher levels of self-rated health and socioeconomic status. The distribution of study visits per season is shown in online supplemental figure 1; a lower proportion of examination 3 visits occurred in the cooler months.

The proportion of participants reporting a recent respiratory infection at each examination was $20.8 \%, 18.7 \%$, $18.2 \%, 17.5 \%$ and $13.5 \%$, respectively. The prevalence of infection varied between $10 \%$ and $32 \%$ depending on study region and month of visit, with lower rates during the warmer months (figure 1). The average concentrations of $\mathrm{PM}_{2.5}, \mathrm{NO}_{2}$ and $\mathrm{NO}_{\mathrm{x}}$ varied by region, but generally declined over the study period (figure 2). There was substantial within-region and between-region variability in pollutant concentrations (figure 3).

In unadjusted models, the risk ratios (95\% CIs) for the associations between short-term $\mathrm{PM}_{2.5}, \mathrm{NO}_{\mathrm{x}}$ and $\mathrm{NO}_{2}$ exposure and report of recent respiratory infection were 1.07 (1.03 to 1.13), 1.23 (1.20 to 1.26) and 1.28 (1.17 to 1.39 ), respectivey. In fully adjusted models, higher average short-term $\mathrm{PM}_{2.5}, \mathrm{NO}_{\mathrm{x}}$ and $\mathrm{NO}_{2}$ exposure was associated with statistically significantly greater risk of reporting a recent respiratory infection at that visit $\left(\mathrm{PM}_{2.5}\right.$ : RR 1.04 (95\% CI: 1.00 to 1.09), $\mathrm{NO}_{\mathrm{x}}: 1.15$ (1.10 to 1.20 ) and $\mathrm{NO}_{2}: 1.21$ (1.10 to 1.33) per interquartile range differences of $5.7 \mu \mathrm{g} / \mathrm{m}^{3}, 33.5 \mathrm{ppb}$ and $14.4 \mathrm{ppb}$, respectively) (figure 4). Results for examination-specific associations were similar, although slightly attenuated and with gradual loss of precision over subsequent examinations (figure 4 and online supplemental table S2). We did not observe statistically significant associations between report of respiratory infection and average long-term exposure (1 year before examination) to any of the pollutants. Results from a short-term exposure sensitivity analysis using average concentrations over a 2-week period before study examination were very similar to those from the 4-week average analysis (online supplemental figure S2) and online supplemental table S2). Additionally, our data did not show evidence of statistically significant modification of the association between short-term exposure to $\mathrm{PM}_{2.5}, \mathrm{NO}_{2}$ and $\mathrm{NO}_{\mathrm{x}}$ and risk of infection by any of the characteristics we examined (online supplemental table S3). 

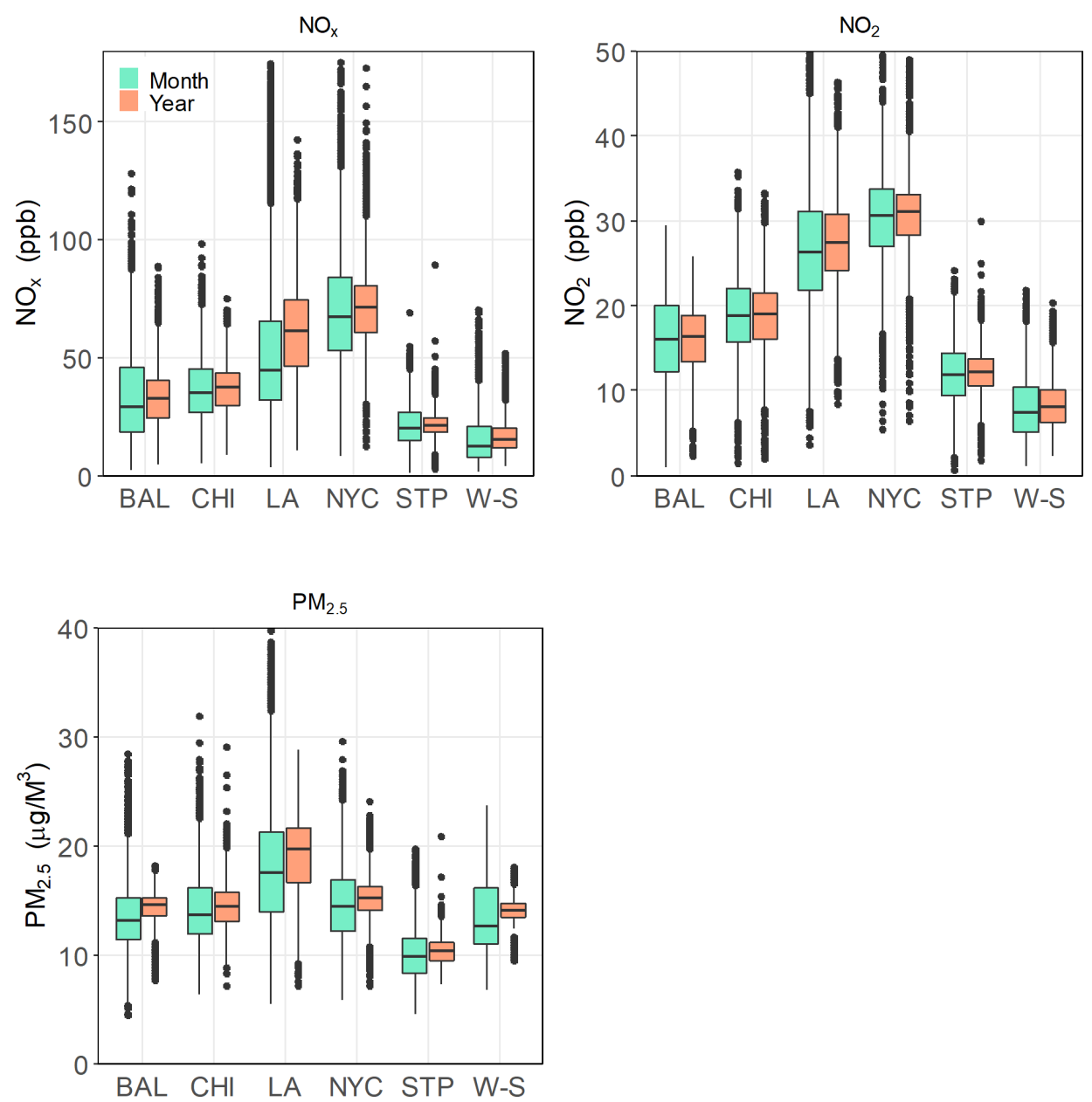

Figure 3 Range of estimated $\mathrm{No}_{x}, \mathrm{NO}_{2}$, and $\mathrm{PM}_{2.5}$ exposures at study participant residential locations over the year (longterm) and the 2-6 weeks (short-term) interval preceding a clinical examination in MESA, by study site. BAL, Baltimore, MD; CHI, Chicago, IL; LA, Los Angeles, CA; NYC, New York City, NY; STP, St Paul, MN; W-S, Winston Salem, NC.MESA, multiethnic study of atherosclerosis.

Quantitative influenza data could only be obtained from one metropolitan area (Los Angeles), and only for the period starting October 2006. Based on these limited data, we did not find clear evidence that the risk for recent respiratory infection is modified by whether the week of the study visit was classified by the $\mathrm{CDC}$ as a influenza week, a designation that denotes a heightened level of circulating influenza-causing pathogens as
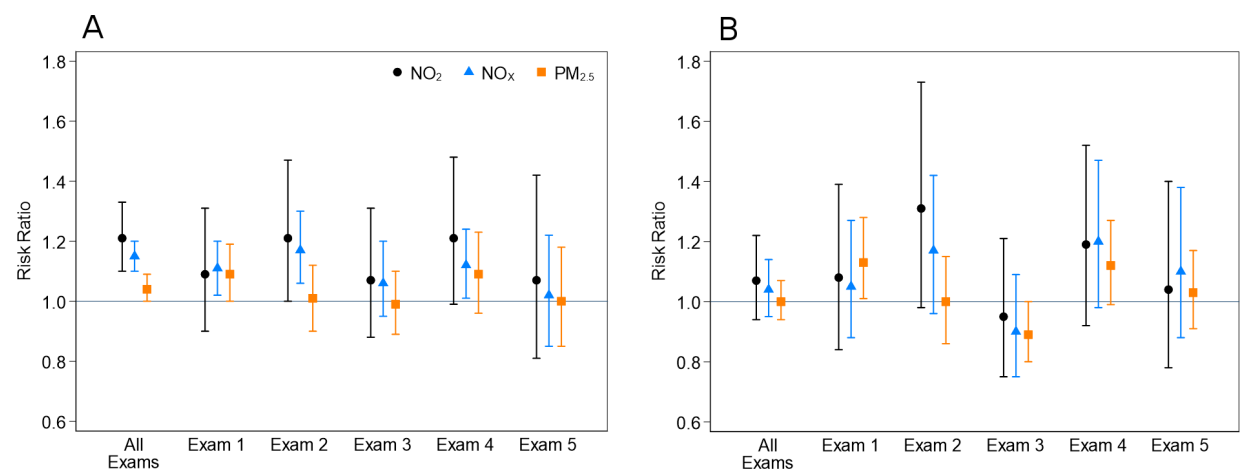

Figure 4 Risk ratios and 95\% Cls for associations between respiratory infection and pollutant exposure in the 2-6 weeks (A) and year (B) before interview, for an IQR increase in average pollutant exposure. Results are from model adjusted for study site, race/ethnicity, sex, age, body mass index, marital status, education level, smoking status (ever/never smoked), employment status, annual income, neighbourhood level socioeconomic index, home ownership, number of household members, having health insurance, whether on medicaid, diabetes diagnosis based on ADA criteria and splines of calendar time (and temperature and relative humidity for short-term exposure analysis). ADA, American Diabeteic Association. 
tested in public health laboratories across the country (online supplemental table S4). Although our data suggested an increased risk of infection for participants with high average short-term exposure to $\mathrm{PM}_{2.5}$ and $\mathrm{NO}_{2}$ during high-relative to low-influenza activity periods in Los Angeles, the CIs are wide due to the reduced sample size in this subset of examinations (online supplemental table S5). Additionally, there was no effect modification by NSES, based on models that included study region by NSES interaction terms.

Restricting the sample to the 4197 participants who completed all five study visits and were eligible for the study at each visit, we obtained very similar results (online supplemental table S6) and online supplemental figure S3). When we excluded febrile illness, the results remained the same (online supplemental table S7). Models that additionally included physical activity and self-reported health status did not materially alter the results.

\section{DISCUSSION}

In a large well-characterised multiethnic cohort observed on up to five occasions over a 12-year period, average exposure to $\mathrm{PM}_{2.5}, \mathrm{NO}_{\mathrm{x}}$ and $\mathrm{NO}_{2}$ in the 2-6 weeks period preceding a clinic visit was associated with report of a recent respiratory infection. The analysis benefited from a validated exposure assessment method developed for this cohort, taking into account changes in participant address and using study-specific monitoring. The model incorporated both regulatory agency and study-specific monitoring to provide refined spatial and temporal contrasts within and between study regions. These findings suggest that short-term variations in fine particulate and traffic-related air pollution may influence susceptibility to acute respiratory infections among adults.

\section{Comparison with previous studies}

Much of the research assessing the association between air pollution and respiratory disease has focused on LRI outcomes among children. ${ }^{41} 42$ Reports have also highlighted the link between air pollution and mortality, hospitalisation and emergency department visits, especially due to pneumonia, asthma and exacerbations of COPD, among adults. ${ }^{43-47}$ However, the evidence base for the role of air pollutants in the acute manifestation of more common respiratory symptoms and infections among ambulatory adults in the general population is more limited. In a case-crossover study of 57000 patients in Beijing, $\mathrm{PM}_{2.5}, \mathrm{PM}_{10}, \mathrm{NO}_{2}, \mathrm{SO}_{2}$ and $\mathrm{CO}$ were associated with outpatient visits for URTI, acute bronchitis and community-acquired pneumonia. ${ }^{48} \mathrm{~A}$ retrospective time series analysis in Hong Kong found significant associations between elevated exposures to $\mathrm{PM}_{10}$, ozone and especially $\mathrm{NO}_{2}$ and general outpatient clinic visits for URTI. ${ }^{49}$ Another Chinese time series study of 1.4 million patient visits for respiratory diseases that included pneumonia and acute bronchitis, reported associations with higher outdoor $\mathrm{PM}_{2.5}, \mathrm{PM}_{10}, \mathrm{NO}_{2}$ and ozone. ${ }^{50}$ In a lesspolluted part of China, $\mathrm{PM}_{2.5}, \mathrm{PM}_{10}$ and $\mathrm{NO}_{2}$ exposures, over the past 7 days were associated with outpatient visits for respiratory disease in a 4year period. ${ }^{51}$

Our study reflects the context of multiple US cities with comparatively lower pollution levels, and leverages highly resolved exposure information and covariate data collected over a long period in which exposure levels varied substantially.

We observed strong temporal trends in both pollutant concentrations and in the rates of illness reporting among participants. Therefore, we deployed strong statistical controls (adjustment for calendar time and seasonality) which greatly reduced potential for these trends to influence the results. It could be argued that this is overadjustment, if in fact these observed long-term secular trends of reduced reporting of respiratory infections were caused by declines in air pollution. In that case, our estimates of effect may be attenuated relative to the true magnitude of effect.

Acute respiratory infections are major drivers of primary healthcare and antibiotic drug utilisation, suggesting that pollution control may have wide-ranging individual and community health benefits. In a recent analysis, daily rates of telephone calls and e-mails, as well as actual provider visits and emergency department visits related to respiratory symptoms were linked to increased $\mathrm{PM}_{2.5}$ levels on that day, with $2.61 \%$ more calls and e-mails and $2.63 \%$ more provider visits per 100000 health insurance programme members per day ${ }^{52}$ The same syndromic surveillance approach also demonstrated increased respiratory-related healthcare utilisation for increases in ozone concentrations. ${ }^{53}$ An advantage of this design, shared with our approach, is the ability to capture subacute symptoms for which a person may not have otherwise sought medical care.

Evidence pointing to a role for air pollutants in morbidity and mortality due to the novel pandemic coronavirus caused by SARS-CoV-2 continues to emerge, although most reports still drawn from ecological study designs because detailed individual-level data are not yet available. ${ }^{54-56}$ Among older adults in the USA, a nationwide study based on county-level COVID-19 death rates suggested that a $1 \mu \mathrm{g} / \mathrm{m}^{3}$ higher $\mathrm{PM}_{2.5}$ exposure was associated with an $11 \%$ increase in COVID-19 mortality. ${ }^{57}$ In Europe, multiple studies have also provided preliminary indications of positive area-level associations between air pollution $\left(\mathrm{PM}_{25}\right.$ and $\left.\mathrm{NO}_{2}\right)$ and COVID-19 severity, including a report associating an additional $1 \mu \mathrm{g} / \mathrm{m}^{3}$ of $\mathrm{PM}_{2.5}$ at the municipality-level with nine extra COVID-19 cases, three extra hospital admissions and one extra death. ${ }^{58-60}$ Initial investigations using limited individuallevel data also point to an increase of approximately $7 \%$ in mortality rate for each additional $1 \mu \mathrm{g} / \mathrm{m}^{3}$ in longterm $\mathrm{PM}_{2.5}$ exposure. ${ }^{61}$ While high-quality representative individual-level data remain scarce, this rapidly evolving body of literature suggests that air pollutants may exacerbate the severity of COVID-19, especially in the presence 
of other key risk factors such as advanced age, obesity, and comorbid health conditions.

\section{Possible mechanisms}

The mechanisms through which pollutants potentially increase the risk of respiratory infection are still being studied. Particulate and gaseous pollutants are thought to cause respiratory injury through induction of oxidative stress and inflammation in the airways. ${ }^{1862}$ Particles are removed through exhalation, mucociliary clearance or phagocytosis by alveolar macrophages; or they may be translocated through respiratory epithelial surfaces. ${ }^{9} 63$ Particle deposition and clearance vary by individual-level factors such as age, sex, smoking status, concomitant conditions like asthma and COPD, activity levels and breathing patterns, which may therefore affect the risk of developing pollutant-related disease. ${ }^{9}$ Particles that remain in the respiratory tract can cause inflammation, oxidative stress, inhibition of mucociliary clearance mechanisms, disruption of epithelial tight junctions and impairment of macrophage antimicrobial phagocytic activity, potentially enhancing susceptibility to respiratory infections. ${ }^{1864}$ There is mounting in vitro and in vivo evidence for the pulmonary immunotoxicity of fine particulate matter, although a clear understanding of the underlying mechanisms remains elusive. ${ }^{65}$ Particulate matter appears to enhance Streptococcus pneumoniae biofilm growth and colonisation of human middle ear epithelium cells in vitro, and to increase pneumococcal colonisation of the nasopharynx in an animal model. ${ }^{66}$

Oxides of nitrogen are absorbed in both the upper respiratory tract and pulmonary regions, and their reactions with surface epithelial fluids may result in oxidative stress, while absorbed components may cause deep lung irritation and immunomodulation of host response to infection, possibly increasing susceptibility or worsening the severity of existing infection. ${ }^{67}$ In the Swiss Cohort Study on Air Pollution and Lung and Heart Disease in Adults (SAPALDIA), increased exposure to $\mathrm{NO}_{2}$ was linked to higher risk of respiratory problems leading to doctor visits among participants with underlying COPD and chronic bronchitis. ${ }^{68}$ This suggests that particulate and traffic-related pollutants may elevate the virulence of secondary pathogenic agents in the event of concurrent exposure in the human respiratory tract, partly through inhibition of immune function. Some investigators have hypothesised that air pollution may increase the mortality risks associated with the novel epidemic Severe Acute Respiratory Syndrome Coronavirus- $2 .{ }^{69}$

\section{Strengths and limitations}

This study has some limitations. Sufficiently detailed CDC influenza activity data for our period of interest were not readily available for most study regions, reducing our ability to assess the interesting potential interactive role of community-level influenza activity on the pollutantillness relationship. The outcomes were self-reported, although trained research staff conducted the interviews consistently over follow-up. In addition, we used outdoor residential pollutant concentrations that do not take into account the actual microenvironments in which participants spend time. Importantly, we utilised high-quality exposure predictions in an ethnically and geographically diverse and well-characterised cohort that permitted ample confounder control and exploitation of fine spatiotemporal variations in exposure.

\section{CONCLUSION AND RECOMMENDATIONS}

Our study provides evidence that higher exposure to $\mathrm{PM}_{2.5}, \mathrm{NO}_{\mathrm{x}}$ and $\mathrm{NO}_{2}$ contributes to an increased risk of common but mostly self-limited respiratory infections. The potential burden of these illnesses-in lost productivity, healthcare utilisation and antibiotic use-suggests that control of particulate and traffic-related pollution may provide substantial individual and societal benefit. In light of the increased attention to respiratory infections in the time of the COVID-19 pandemic, these results also may provide an insight into the potential role of pollutants in modifying the risk of novel viral infections. Given the known deleterious effects of pollutants on the respiratory system, including increasing the risk of infections, and preliminary linkages to COVID-19 morbidity and mortality, it is suggested that reducing pollutant exposure may prevent severe illness and death due to COVID-19. Because respiratory infections, possibly including COVID-19, will remain major health problems among adults, two recommendations can be inferred from our study. First, it may be beneficial for older adults who spend substantial amounts of time in the home to utilise air purification equipment such as filters. Second, multipronged regulatory actions to control pollution at the societal level remain critical public health priorities including science-based adjusments of air quality standards and concerted efforts and resources in areas with high concentrations of particulate and traffic-related pollutants.

Contributors The authors meet criteria for authorship as recommended by the International Committee of Medical Journal Editors, take responsibility for the integrity of the work as a whole, contributed to the writing and reviewing of the manuscript and have given final approval for the version to be published. KK, CME and JK had full access to the data in this study and took complete responsibility for the integrity of the data and accuracy of the data analysis. KK wrote the first draft of the manuscript. KK, CME and JK were involved in the acquisition of data and data analysis/interpretation. KK, CME, SV, AH and JK were involved in conception/ design and data analysis/interpretation. All authors were involved in critical revision of the manuscript for important intellectual content.

Funding This publication was developed under a STAR research assistance agreements, No. RD831697 (MESA Air) and RD-83830001 (MESA Air Next Stage), awarded by the US Environmental Protection Agency. It has not been formally reviewed by the EPA. Multiethnic study of atherosclerosis (MESA) was supported by contracts 75N92020D00001, HHSN268201500003I, N01-HC95159, 75N92020D00005, N01-HC-95160, 75N92020D00002, N01-HC-95161, 75N92020D00003, N01-HC-95162, 75N92020D00006, N01-HC-95163, 75N92020D00004, N01-HC-95164, 75N92020D00007, N01-HC-95165, N01-HC95166, N01-HC-95167, N01-HC-95168 and N01-HC-95169 from the National Heart, Lung, and Blood Institute, and by grants UL1-TR-000040, UL1-TR-001079 and UL1-TR-001420 from the National Center for Advancing Translational Sciences (NCATS). The authors thank the other investigators, the staff and the participants 
of the MESA study for their valuable contributions. A full list of participating MESA investigators and institutions can be found at http://www.mesa-nhlbi.org. This paper was also supported by the National Institutes of Environmental Health Sciences, through grant P30ES007033.

Disclaimer The views expressed in this document are solely those of the authors and the EPA does not endorse any products or commercial services mentioned in this publication

Competing interests None declared.

Patient consent for publication Not required.

Ethics approval Institutional review boards at all study sites gave approval and each participant provided written informed consent.

Provenance and peer review Not commissioned; externally peer reviewed.

Data availability statement № data are available. The data contain confidential study participant information that the authors are not permitted to share data directly.

Supplemental material This content has been supplied by the author(s). It has not been vetted by BMJ Publishing Group Limited (BMJ) and may not have been peer-reviewed. Any opinions or recommendations discussed are solely those of the author(s) and are not endorsed by BMJ. BMJ disclaims all liability and responsibility arising from any reliance placed on the content. Where the content includes any translated material, BMJ does not warrant the accuracy and reliability of the translations (including but not limited to local regulations, clinical guidelines, terminology, drug names and drug dosages), and is not responsible for any error and/or omissions arising from translation and adaptation or otherwise.

Open access This is an open access article distributed in accordance with the Creative Commons Attribution Non Commercial (CC BY-NC 4.0) license, which permits others to distribute, remix, adapt, build upon this work non-commercially, and license their derivative works on different terms, provided the original work is properly cited, appropriate credit is given, any changes made indicated, and the use is non-commercial. See: http://creativecommons.org/licenses/by-nc/4.0/.

\section{REFERENCES}

1 Lelieveld J, Evans JS, Fnais M, et al. The contribution of outdoor air pollution sources to premature mortality on a global scale. Nature 2015:525:367-71.

2 Cohen AJ, Brauer M, Burnett R, et al. Estimates and 25-year trends of the global burden of disease attributable to ambient air pollution: an analysis of data from the global burden of diseases study 2015. Lancet 2017;389:1907-18.

3 World Health Organization Occupational and Environmental Health Team. WHO Air quality guidelines for particulate matter, ozone, nitrogen dioxide and sulfur dioxide : global update 2005 : summary of risk assessment. Geneva: World Health Organization, 2006.

4 Rice MB, Ljungman PL, Wilker EH, et al. Long-term exposure to traffic emissions and fine particulate matter and lung function decline in the Framingham heart study. Am J Respir Crit Care Med 2015;191:656-64.

5 Gehring U, Gruzieva O, Agius RM, et al. Air pollution exposure and lung function in children: the escape project. Environ Health Perspect 2013;121:1357-64.

6 Young MT, Sandler DP, DeRoo LA, et al. Ambient air pollution exposure and incident adult asthma in a nationwide cohort of U.S. women. Am J Respir Crit Care Med 2014;190:914-21.

7 Peacock JL, Anderson HR, Bremner SA, et al. Outdoor air pollution and respiratory health in patients with COPD. Thorax 2011;66:591-6.

8 Wang M, Aaron CP, Madrigano J, et al. Association between longterm exposure to ambient air pollution and change in quantitatively assessed emphysema and lung function. JAMA 2019;322:546-56.

9 IARC. IARC monographs on the evaluation of carcinogenic risks to humans - volume 109: outdoor air pollution. Lyon, France: IARC, 2016.

10 Lagorio S, Forastiere F, Pistelli R, et al. Air pollution and lung function among susceptible adult subjects: a panel study. Environ Health 2006;5:11.

11 Int Panis L, Provost EB, Cox B, et al. Short-Term air pollution exposure decreases lung function: a repeated measures study in healthy adults. Environ Health 2017;16:60.

12 Guarnieri M, Balmes JR. Outdoor air pollution and asthma. Lancet 2014;383:1581-92.

13 Ghosh R, Joad J, Benes I, et al. Ambient nitrogen oxides exposure and early childhood respiratory illnesses. Environ Int 2012;39:96-102.
14 Horne BD, Joy EA, Hofmann MG, et al. Short-term elevation of fine particulate matter air pollution and acute lower respiratory infection. Am J Respir Crit Care Med 2018:198:759-66.

15 Pirozzi CS, Jones BE, VanDerslice JA, et al. Short-term air pollution and incident pneumonia. A case-crossover study. Ann Am Thorac Soc 2018;15:449-59.

16 Dominici F, Peng RD, Bell ML, et al. Fine particulate air pollution and hospital admission for cardiovascular and respiratory diseases. JAMA 2006;295:1127-34.

17 Croft DP, Zhang W, Lin S, et al. The association between respiratory infection and air pollution in the setting of air quality policy and economic change. Ann Am Thorac Soc 2019;16:321-30.

18 Ciencewicki J, Jaspers I. Air pollution and respiratory viral infection. Inhal Toxicol 2007:19:1135-46.

19 Holgate ST, Sandström T, Frew AJ, et al. Health effects of acute exposure to air pollution. Part I: healthy and asthmatic subjects exposed to diesel exhaust. Res Rep Health Eff Inst 2003;112:1-30.

20 Goldizen FC, Sly PD, Knibbs LD. Respiratory effects of air pollution on children. Pediatr Pulmonol 2016:51:94-108.

21 Maclntyre EA, Gehring U, Mölter A, et al. Air pollution and respiratory infections during early childhood: an analysis of 10 European birth cohorts within the escape project. Environ Health Perspect 2014;122:107-13.

22 Psoter KJ, De Roos AJ, Mayer JD, et al. Fine particulate matter exposure and initial Pseudomonas aeruginosa acquisition in cystic fibrosis. Ann Am Thorac Soc 2015;12:385-91.

23 Goss $\mathrm{CH}$, Newsom SA, Schildcrout JS, et al. Effect of ambient air pollution on pulmonary exacerbations and lung function in cystic fibrosis. Am J Respir Crit Care Med 2004;169:816-21.

24 Psoter KJ, De Roos AJ, Wakefield J, et al. Air pollution exposure is associated with MRSA acquisition in young U.S. children with cystic fibrosis. BMC Pulm Med 2017:17:106.

25 GBD 2016 Lower Respiratory Infections Collaborators. Estimates of the global, regional, and national morbidity, mortality, and aetiologies of lower respiratory infections in 195 countries, 1990-2016: a systematic analysis for the global burden of disease study 2016 . Lancet Infect Dis 2018:18:1191-210.

26 Ottmani S-E, Scherpbier R, Chaulet P. Respiratory care in primary care services: a survey in 9 countries. WHO/HTM/TB/2004.333. Geneva: WHO, 2004.

27 Zaas AK, Garner BH, Tsalik EL, et al. The current epidemiology and clinical decisions surrounding acute respiratory infections. Trends Mol Med 2014;20:579-88

28 Shapiro DJ, Hicks LA, Pavia AT, et al. Antibiotic prescribing for adults in ambulatory care in the USA, 2007-09. J Antimicrob Chemother 2014;69:234-40.

29 Grigg J, Pollution A. Air pollution and respiratory infection: an emerging and troubling association. Am J Respir Crit Care Med 2018;198:700-1.

30 Bild DE, Bluemke DA, Burke GL, et al. Multi-ethnic study of atherosclerosis: objectives and design. Am J Epidemiol 2002;156:871-81.

31 Kaufman JD, Adar SD, Allen RW, et al. Prospective study of particulate air pollution exposures, subclinical atherosclerosis and clinical cardiovascular disease: the multi-ethnic study of atherosclerosis and air pollution (MESA air). Am J Epidemiol 2012;176:825-37.

32 Cohen MA, Adar SD, Allen RW, et al. Approach to estimating participant pollutant exposures in the multi-ethnic study of atherosclerosis and air pollution (MESA air). Environ Sci Technol 2009;43:4687-93.

33 Keller JP, Olives C, Kim S-Y, et al. A unified spatiotemporal modeling approach for predicting concentrations of multiple air pollutants in the multi-ethnic study of atherosclerosis and air pollution. Environ Health Perspect 2015;123:301-9.

34 Lindström J, Szpiro AA, Sampson PD, et al. A flexible spatiotemporal model for air pollution with spatial and spatio-temporal covariates. Environ Ecol Stat 2014;21:411-33.

35 Szpiro AA, Sampson PD, Sheppard L, et al. Predicting Intra-Urban variation in air pollution concentrations with complex spatiotemporal dependencies. Environmetrics 2009;21:n/a-31.

36 Genuth S, Alberti KGMM, Bennett P, et al. Follow-up report on the diagnosis of diabetes mellitus. Diabetes Care 2003;26:3160-7.

37 Grundy SM, Brewer HB, Cleeman JI, et al. Definition of metabolic syndrome: report of the National heart, lung, and blood Institute/ American heart association conference on scientific issues related to definition. Circulation 2004;109:433--8.

38 Hajat A, Diez-Roux AV, Adar SD, et al. Air pollution and individual and neighborhood socioeconomic status: evidence from the multiethnic study of atherosclerosis (MESA). Environ Health Perspect 2013;121:1325-33 
39 Zou GY, Donner A. Extension of the modified poisson regression model to prospective studies with correlated binary data. Stat Methods Med Res 2013;22:661-70.

40 Centers for Disease Control and Prevention. FluView: U.S. influenza surveillance system: purpose and methods Atlanta, GA: CDC, 2019. Available: [Available from: https://www.cdc.gov/flu/weekly/overview. htm\#anchor_1539281266932 accessed December 18, 2019.

41 Nhung NTT, Amini H, Schindler C, et al. Short-term association between ambient air pollution and pneumonia in children: a systematic review and meta-analysis of time-series and casecrossover studies. Environ Pollut 2017;230:1000-8.

42 Berhane K, Chang C-C, McConnell R, et al. Association of changes in air quality with bronchitic symptoms in children in California, 1993-2012. JAMA 2016;315:1491-501.

43 Neupane B, Jerrett M, Burnett RT, et al. Long-term exposure to ambient air pollution and risk of hospitalization with communityacquired pneumonia in older adults. Am J Respir Crit Care Med 2010;181:47-53.

44 Anderson HR, Favarato G, Atkinson RW. Long-term exposure to air pollution and the incidence of asthma: meta-analysis of cohort studies. Air Qual Atmos Health 2013;6:47-56.

45 Faustini A, Stafoggia M, Colais $P$, et al. Air pollution and multiple acute respiratory outcomes. Eur Respir J 2013;42:304-13.

46 DeVries R, Kriebel D, Sama S. Outdoor air pollution and COPDRelated emergency department visits, hospital admissions, and mortality: a meta-analysis. COPD 2017;14:113-21.

47 Medina-Ramón M, Zanobetti A, Schwartz J. The effect of ozone and PM10 on hospital admissions for pneumonia and chronic obstructive pulmonary disease: a national multicity study. Am J Epidemiol 2006;163:579-88.

48 Li R, Jiang N, Liu Q, et al. Impact of air pollutants on outpatient visits for acute respiratory outcomes. Int J Environ Res Public Health 2017;14:47.

49 Tam WWS, Wong TW, Ng L, et al. Association between air pollution and general outpatient clinic consultations for upper respiratory tract infections in Hong Kong. PLoS One 2014;9:e86913.

50 Wang S, Li Y, Niu A, et al. The impact of outdoor air pollutants on outpatient visits for respiratory diseases during 2012-2016 in Jinan, China. Respir Res 2018;19:246-46.

51 Liu Y, Chen S, Xu J, et al. The association between air pollution and outpatient and inpatient visits in Shenzhen, China. Int $J$ Environ Res Public Health 2018;15:178.

52 Fuller $\mathrm{CH}$, Roblin D, Jones J. Using syndromic surveillance to evaluate the respiratory effects of fine particulate matter. Ann Am Thorac Soc 2019;16:930-3.

53 Fuller CH, Jones JW, Roblin DW. Evaluating changes in ambient ozone and respiratory-related healthcare utilization in the Washington, DC metropolitan area. Environ Res 2020;186:109603.
54 Ali N, Islam F. The effects of air pollution on COVID-19 infection and Mortality-A review on recent evidence. Front Public Health 2020;8:580057.

55 Copat C, Cristaldi A, Fiore M, et al. The role of air pollution (PM and $\mathrm{NO}_{2}$ ) in COVID-19 spread and lethality: A systematic review. Environ Res 2020;191:110129.

56 Villeneuve PJ, Goldberg MS. Methodological considerations for epidemiological studies of air pollution and the SARS and COVID-19 coronavirus outbreaks. Environ Health Perspect 2020;128:095001.

57 Wu X, Nethery RC, Sabath MB, et al. Air pollution and COVID-19 mortality in the United States: strengths and limitations of an ecological regression analysis. Sci Adv 2020;6:eabd4049.

58 Conticini E, Frediani B, Caro D. Can atmospheric pollution be considered a co-factor in extremely high level of SARS-CoV-2 lethality in northern Italy? Environ Pollut 2020;261:114465.

59 Cole MA, Ozgen C, Strobl E. Air pollution exposure and Covid-19 in Dutch municipalities. Environ Resour Econ 2020;76:581-610.

60 Konstantinoudis G, Padellini T, Bennett J, et al. Long-term exposure to air-pollution and COVID-19 mortality in England: a hierarchical spatial analysis. Environ Int 2021;146:106316.

61 López-Feldman A, Heres D, Marquez-Padilla F. Air pollution exposure and COVID-19: a look at mortality in Mexico City using individual-level data. Sci Total Environ 2021;756:143929.

62 Aust AE, Ball JC, Hu AA, et al. Particle characteristics responsible for effects on human lung epithelial cells. Res Rep Health Eff Inst 2002;110:1-65.

63 Oberdorster G. Lung clearance of inhaled insoluble and soluble particles. J Aerosol Med 1988;1:289-330.

64 Ling SH, van Eeden SF. Particulate matter air pollution exposure: role in the development and exacerbation of chronic obstructive pulmonary disease. Int J Chron Obstruct Pulmon Dis 2009;4:233-43.

65 Wei T, Tang M. Biological effects of airborne fine particulate matter $\left(\mathrm{PM}_{25}\right)$ exposure on pulmonary immune system. Environ Toxicol Pharmacol 2018;60:195-201.

66 Yadav MK, Go YY, Jun I, et al. Urban particles elevated Streptococcus pneumoniae biofilms, colonization of the human middle ear epithelial cells, mouse nasopharynx and transit to the middle ear and lungs. Sci Rep 2020;10:5969.

67 Han X, Naeher LP. A review of traffic-related air pollution exposure assessment studies in the developing world. Environ Int 2006;32:106-20.

68 Mehta AJ, Schindler C, Perez L, et al. Acute respiratory health effects of urban air pollutants in adults with different patterns of underlying respiratory disease. Swiss Med Wkly 2012;142:w13681.

69 Wu X, Nethery RC, Sabath BM, et al. Exposure to air pollution and COVID-19 mortality in the United States: a nationwide crosssectional study. medRxiv 2020. doi:10.1101/2020.04.05.20054502. [Epub ahead of print: 07 Apr 2020]. 